Article

\title{
Chemical Vapour Deposition of Graphene for Durable Anticorrosive Coating on Copper
}

\author{
Dali Ji ${ }^{1}$, Xinyue Wen ${ }^{1}$, Tobias Foller ${ }^{1}$, Yi You ${ }^{2}$, Fei Wang ${ }^{1}$ and Rakesh Joshi ${ }^{1, * \mathbb{C}}$ \\ 1 School of Materials Science and Engineering, University of New South Wales, Sydney 2052, Australia; \\ dali.ji@student.unsw.edu.au (D.J.); xinyue.wen@unsw.edu.au (X.W.); t.foller@student.unsw.edu.au (T.F.); \\ fei.wang3@unsw.edu.au (F.W.) \\ 2 Department of Physics and Astronomy, University of Manchester, Manchester M13 9PL, UK; \\ yi.you@manchester.ac.uk \\ * Correspondence: r.joshi@unsw.edu.au; Tel.: +61-(0)449534314
}

Received: 11 November 2020; Accepted: 10 December 2020; Published: 14 December 2020

check for updates

\begin{abstract}
Due to the excellent chemical inertness, graphene can be used as an anti-corrosive coating to protect metal surfaces. Here, we report the growth of graphene by using a chemical vapour deposition (CVD) process with ethanol as a carbon source. Surface and structural characterisations of CVD grown films suggest the formation of double-layer graphene. Electrochemical impedance spectroscopy has been used to study the anticorrosion behaviour of the CVD grown graphene layer. The observed corrosion rate of $8.08 \times 10^{-14} \mathrm{~m} / \mathrm{s}$ for graphene-coated copper is 24 times lower than the value for pure copper which shows the potential of graphene as the anticorrosive layer. Furthermore, we observed no significant changes in anticorrosive behaviour of the graphene coated copper samples stored in ambient environment for more than one year.
\end{abstract}

Keywords: graphene; anti-corrosion; chemical vapour deposition; ethanol

\section{Introduction}

Corrosion is a naturally occurring phenomenon, which describes the tendency of a material to react with other chemicals resulting in deterioration of stability [1]. A feasible method to reduce the corrosion damage is by coating the metal with a stable and anticorrosive layer. Nevertheless, those traditional protective coatings, including organic layers [2-4], polymers coating [5,6], oxide layers [7], and inert metals [8] have their limitations. For example, the high thickness is necessary for traditional anticorrosive layers to ensure protective effects [9-12]. And some organic or polymers coatings such as epoxy coating can rapidly age under high temperature [13]. Therefore, it is in high demand to solve the corrosion problems by exploiting new chemically inert protective coating materials.

Graphene is a hexagonal two-dimension atomically thin film of carbon. It exhibits many unique properties, including outstanding mechanical properties [14-18] and remarkable chemical inertness in the erosive environment $[19,20]$. Moreover, graphene also shows exceptional high-temperature stability [21,22]. These properties enable graphene as an ideal candidate for anti-corrosion coating. Additionally, according to Bunch et al., the monolayer graphene sheet is impermeable to any gas molecules, which is essential as an anti-corrosion coating [23]. Chen et al. firstly found that chemical vapour deposition (CVD) graphene grown on $\mathrm{Cu}$ and $\mathrm{Cu} / \mathrm{Ni}$ substrates shows an active resistance against hydrogen peroxide [24]. Kirkland et al. further demonstrated the anticorrosive mechanism for a short time test of graphene coating and reported the impermeability and stability of graphene $[25,26]$. Schriver et al. and Zhou et al. conducted short term and long-term anticorrosive behaviour of graphene coating and suggested that anticorrosive behaviour is better for the short term. According to the authors, the oxidizing agent can permeate through defects in graphene leading to a faster galvanic 
corrosion for the long term corrosion mesurements $[27,28]$. Authors suggested that the permeation of oxidising agent creates a corrosion products between copper and graphene which further accelerates the corrosion rate by exfoliation of graphene [29]. In another works, Ying et al. and Yinghao et al. demonstrated that double layer graphene can efficiently protect the copper from being corroded in the long term. Braeuninger-Weimer et al. have studied the effect of copper crystal orientation on graphene growth and anticorrosive properties. According to the authors, $\mathrm{Cu}$ crystal orientations such as (011) exhibiting weak interaction force with graphene cannot prevent the intercalation of corrosive agents, hence resulting into corrosion [30]. However, copper with crystal orientations as $\mathrm{Cu}(111)$ and $\mathrm{Cu}(311)$ offer relatively strong interfacial coupling with graphene leading to an improved anticorrosive behaviour $[30,31]$.

To improve the coating quality, gas precursors such as methane $\left(\mathrm{CH}_{4}\right)$ have been used in these papers because it provides stable carbon flow [32,33]. However, the average growth temperature of experiments was around $1000{ }^{\circ} \mathrm{C}$, and the growth pressure was high $[12,19,26,34]$. Here, we report the CVD graphene using ethanol as a carbon source for anticorrosive coating. We observed that the graphene coating prepared by this method could provide considerable corrosion resistance over the large area of the surface.

\section{Materials and Methods}

\subsection{Growth of Graphene}

In this experiment, we used the polycrystalline copper (A\&E Metals Merchants, Sydney Australia, size $2 \mathrm{~cm} \times 1.5 \mathrm{~cm} \times 0.1 \mathrm{~mm}$ ) as the substrate of graphene coating. All of the substrates were originally sonicated in acetone solution (100\%) for $5 \mathrm{~min}$ to remove organic residues. After this, the ethanol solution $(100 \%)$ and deionized water were used to wash samples three times to remove the residual solution followed by heat treatment at $900{ }^{\circ} \mathrm{C}$ for $20 \mathrm{~min}$ to transform polycrystalline copper into single crystalline $\mathrm{Cu}(111)$. The polycrystalline copper substrate after the heat treatment is shown in Figure $1 \mathrm{a}$. Here, it is worth to mention that no pre-treatment such as extra polishing/electroplating has been done on the copper substrate.
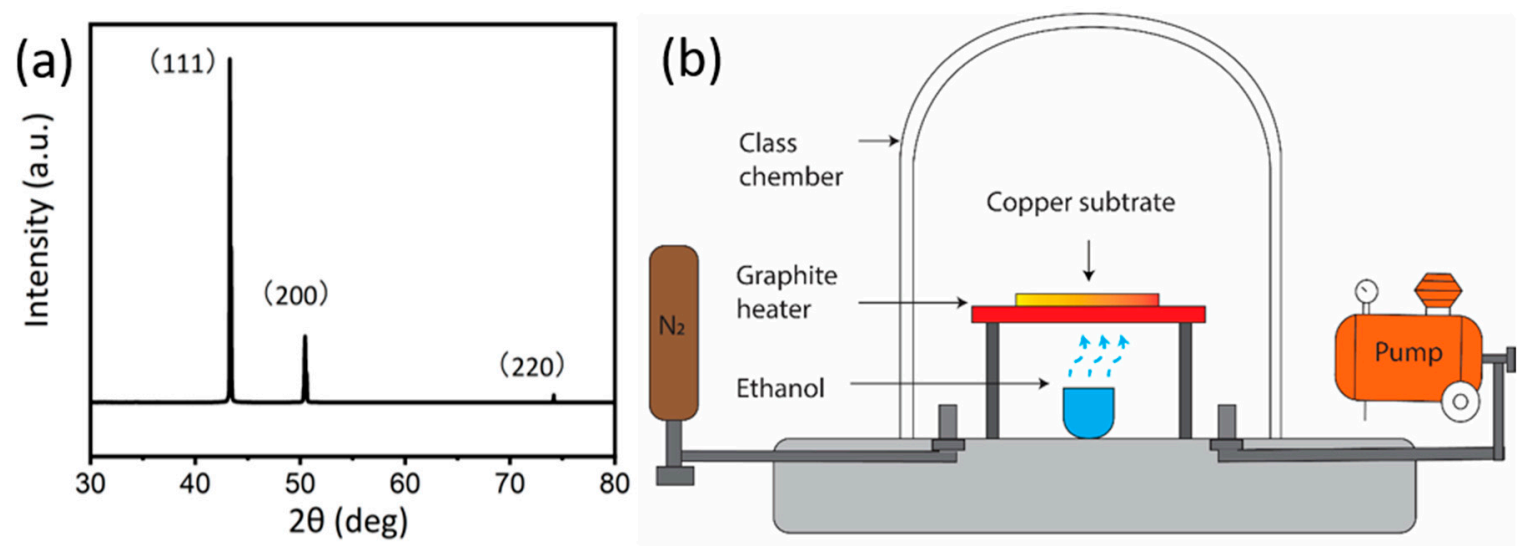

Figure 1. (a) The X-ray diffraction (XRD) pattern of $\mathrm{Cu}$ substrate showing polycrystalline nature.

(b) The schematic diagram of the chemical vapour deposition (CVD) system.

The schematic of the CVD system (Microphase Pty Ltd., Manila, Philippines, Maximum temperature $900{ }^{\circ} \mathrm{C}$ ) is shown in Figure 1, which has been reported in our previous research [35]. The copper substrates were heated by a graphite joule heater which is connected to a direct current temperature controller. An Alumina crucible under the graphite heater was used to load the ethanol precursor. Ethanol has a simple molecular structure, and it is relatively abundant, non-poisonous, and less flammable than traditional gaseous precursor [35,36], hence, it was chosen as our carbon source. The graphene growth was conducted under a stable vacuum of 10 torr $(\sim 1.3 \mathrm{kPa})$. We have used a 
rotary pump (ULVAC G-20DA) with $100 \mathrm{~W} 24 \mathrm{~L} / \mathrm{min}(100 \mathrm{~V} 50 \mathrm{~Hz})$. Prior to the growth, the glass vacuum chamber was purged with $\mathrm{N}_{2}$ three times to remove any residual air for growth process. Our experimental conditions allow a heating rate of $18^{\circ} \mathrm{C} / \mathrm{s}$ and cooling rate of $7^{\circ} \mathrm{C} / \mathrm{s}$. To optimize the growth parameters for graphene growth, a set of temperature and growth times were selected (shown in Table 1), and each condition was repeated at least three times to ensure the reproducibility of the results. The infrared thermometer (Model: RS232c output type tmh9) was used for temperature measuring. For clarity, samples are labelled as G-growth temperature-growth time. For example, the sample grown at $750{ }^{\circ} \mathrm{C}$ for $5 \mathrm{~min}$ is referred to as G-750-5, here G stands for graphene.

Table 1. Summary of CVD conditions.

\begin{tabular}{lccc}
\hline Growth Temperature (Growth Time-5 min) & $750{ }^{\circ} \mathrm{C}$ & $800{ }^{\circ} \mathrm{C}$ & $850{ }^{\circ} \mathrm{C}$ \\
\hline Growth time (growth temperature $\left.-850{ }^{\circ} \mathrm{C}\right)$ & 2 min & 6 min & $10 \mathrm{~min}$ \\
\hline
\end{tabular}

\subsection{Characterization}

CVD grown films on the copper surface were thoroughly characterised. Scanning electron microscopy (F.E.I. Nova NanoSEM 230 and NanoSEM 450) was employed to investigate the surface morphology, and Raman spectra were recorded on a Renishaw inVia with $532 \mathrm{~nm}$ excitation laser to confirm the crystallinity and quality of graphene. Considering the possible surface inhomogeneity, at least three different spots on the surface were investigated to determine the characteristics of CVD grown films. The presented spectra are representative curves with baseline corrected.

Potentiodynamic polarization and electrochemical impedance spectroscopy (EIS) study was conducted using a Versatile Multi-potentiostat VSP300 with EC-lab software to process the electrochemical data. A glass corrosion cell with the three-electrodes system was used for the electrochemical measurements with a platinum wire as a counter electrode, $\mathrm{Ag} / \mathrm{AgCl}$ electrode as a reference electrode, and $\mathrm{NaCl}$ solution (3.5\%) as an electrolyte at room temperature of $23 \pm 1{ }^{\circ} \mathrm{C}$. In our measurements, the open circuit potential was monitored for the first $30 \mathrm{~min}$ to ensure that the system is operating in high stability. The scan rate of potentiodynamic polarization curves was chosen at $0.5 \mathrm{mV} / \mathrm{s}$ in the range $-250 \mathrm{mV}$ to $250 \mathrm{mV}$. EIS tests were conducted by using a sinusoidal potential wave with an amplitude of $10 \mathrm{mV}$ at corrosion potential and the frequencies measuring impedance response between $1 \mathrm{MHz}$ and $10 \mathrm{MHz}$. All the above tests were repeated at least three times to ensure the reproducibility of the results.

\section{Results and Discussion}

As factors such as coverage, layer numbers, and defects can affect the anticorrosive ability of graphene, we optimized the growth parameter before the corrosion test. CVD growth on the copper substrate was studied as a function of growth time and temperature. In our study, we firstly varied the growth temperature by keeping the time constant as $5 \mathrm{~min}$. We analysed the films grown on the substrate using e scanning electron microscopy. Figure 2a shows the typical morphology of the G-750-5. Figure 2d shows the Raman spectra of black areas on the surface. Raman spectra showed a broad $\mathrm{D}\left(\sim 1350 \mathrm{~cm}^{-1}\right)$ and G peak $\left(\sim 1580 \mathrm{~cm}^{-1}\right)$ as well as a very low intensity of the 2D peak (around $2700 \mathrm{~cm}^{-1}$ ) suggesting the formation of graphitic structure [37,38]. Furthermore, the full width at half maximum (FWHM) values of $2 \mathrm{D}$ peaks was around 90 , and the ratio of $\mathrm{D}$ peak and $\mathrm{G}$ peak $\left(\mathrm{I}_{\mathrm{D}} / \mathrm{I}_{\mathrm{G}}\right)$ is close to 1 (Figure 2e), indicating the disorder [38]. 

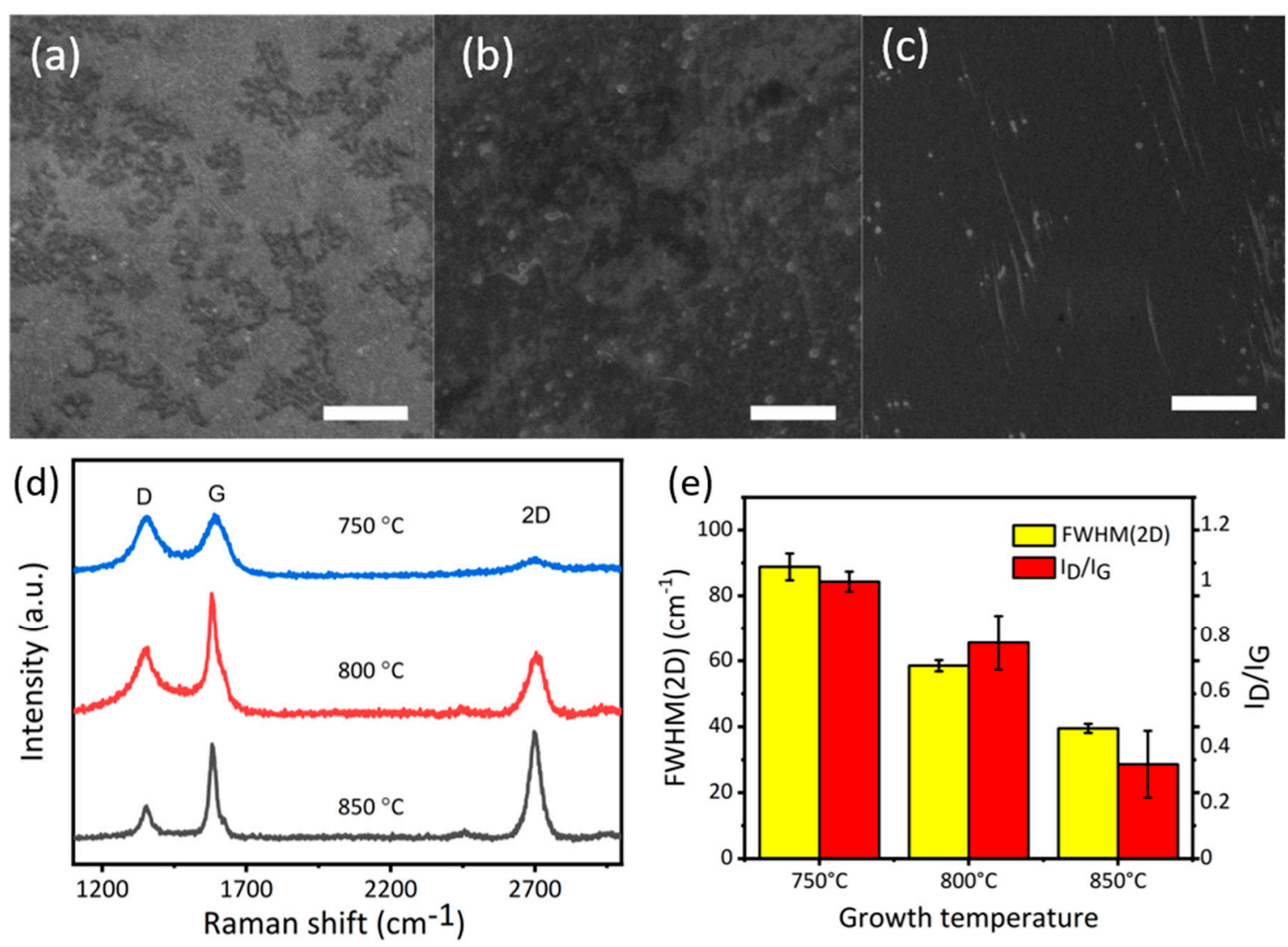

Figure 2. (a) Scanning electron microscope (SEM) image of G-750-5; (b) SEM image of G-800-5 (c) SEM image of G-850-5; (d) Raman spectra of samples grown at $750{ }^{\circ} \mathrm{C}, 800{ }^{\circ} \mathrm{C}$, and $850{ }^{\circ} \mathrm{C}$; (e) The full width at half maximum values of $2 \mathrm{D}$ peaks (full width at half maximum (FWHM)(2D)) and the ratio of D peak and $G$ peak $\left(\mathrm{I}_{\mathrm{D}} / \mathrm{I}_{\mathrm{G}}\right)$; scale bar $(\mathbf{a}-\mathbf{c}) 3 \mu \mathrm{m}$.

In the second set of experiments, when the temperature was ramped up to $800{ }^{\circ} \mathrm{C}$, the coverage of carbon area increased which is possibly due to the formation of graphene (SEM image, Figure 2b). Raman spectrum indicates an increase in the intensity of G peak, suggesting an increase in the degree of crystallization of carbon (Figure 2d). Another obvious change is the FWHM (2D peak) values for the sample G-850-5 decreasing to $~ 55$ (Figure 2e), which is, however, still higher than the value reported for graphene in the past [38]. This study suggests that the film on the substrate is few (5)-layer graphene with a high ID/IG ratio indicating the presence of defects [37,38]. Furthermore, in comparison to samples G-800-5, the surface of the samples G-850-5 is more uniform with better coverage (Figure 2c). Raman spectra can also demonstrate this well-organized trend. In Figure 2e, the 2D peak of G-850-5 is sharp and symmetrical with FWHM values of it about $39 \mathrm{~cm}^{-1}$, suggesting a high level of crystallization and the formation of bilayer graphene $[19,38]$ with low ratio of the intensity of $D$ peak to $G$ peak $\left(I_{D} / I_{G}\right)$; value of about 0.3 [38]. The above study suggested that the graphitic structure is more ordered with the increase in temperature.

After determining the optimal temperature of $850^{\circ} \mathrm{C}$ for graphene growth, the effect of growth time ( $2 \mathrm{~min}, 6 \mathrm{~min}$, and $10 \mathrm{~min}$ ) on graphene growth has been analysed at $850{ }^{\circ} \mathrm{C}$. Carbon flakes grown at this temperature 2 min were in the shape of small black dots or lines (Figure 3). Raman spectra of this sample presented a low-intensity $G$ peak and a broad 2D peak, which is an indicator of graphite $[37,38]$. When growth time increases to $6 \mathrm{~min}$ (G-850-6 SEM-Figure 3b) the surface is fully covered by the film of double-layer graphene, as illustrated in Raman spectra. It can be seen from the SEM images and Raman spectra that the samples G-850-6 and 850-5 have similar nature, indicating the high stability of the method. When growth time increases to $10 \mathrm{~min}$ (sample G-850-10), a degradation in films quality can be observed using Raman spectra analysis (Figure 3d). However, the SEM image showed a fully 
covered carbon layer. This might be due the fact that the excess alcohol vapours cannot be straightaway removed and allow the formation of excess graphitic layers on substrate with defects [37,38]. To sum up, the optimal growth condition for graphene growth is at $850{ }^{\circ} \mathrm{C}$ for $5-6 \mathrm{~min}$, which is more effective to produce bilayer graphene in comparison to the existing methods [29,31,39].
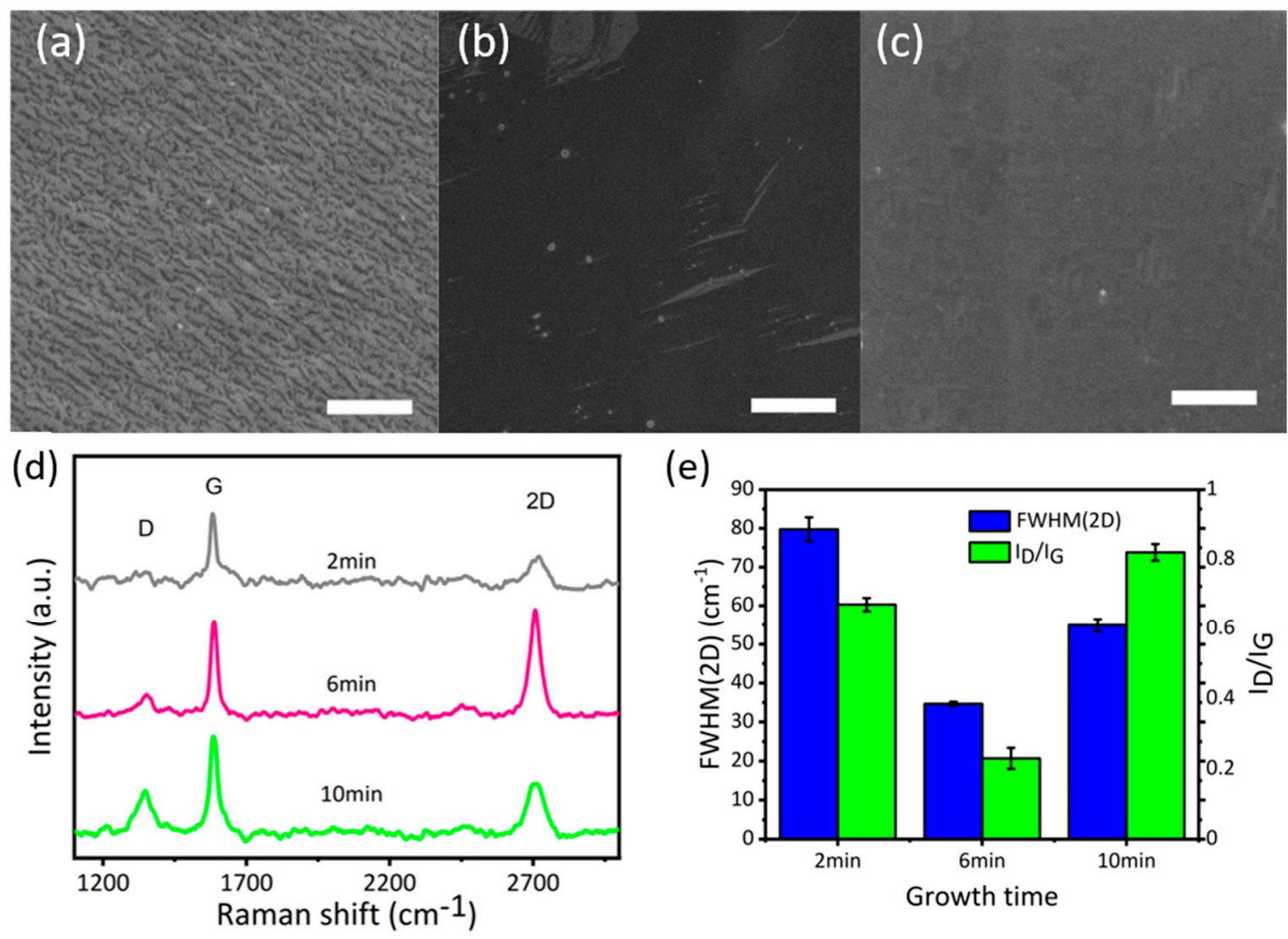

(e)

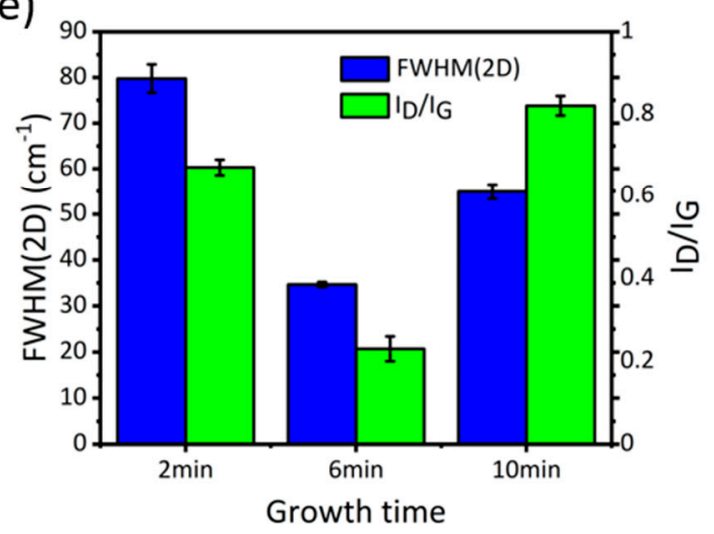

Figure 3. (a) SEM image of G-850-2; (b) SEM image of G-850-6; (c) SEM image of 1G-850-10; (d) Raman spectra of graphene samples grown in $2 \mathrm{~min}, 6 \mathrm{~min}$ and $10 \mathrm{~min}$; (e) $\mathrm{FWHM}(2 \mathrm{D})$ and $\mathrm{I}_{\mathrm{D}} / \mathrm{I}_{\mathrm{G}}$ of graphene samples grown in $2 \mathrm{~min}, 6 \mathrm{~min}$, and $10 \mathrm{~min}$; scale bar $(\mathbf{a}-\mathbf{c}) 3 \mu \mathrm{m}$.

The above study suggests that a temperature of $850{ }^{\circ} \mathrm{C}$ and growth time of $6 \mathrm{~min}$ is the optimized condition to get good quality graphene films with high coverage. These samples were chosen for anti-corrosion test using an electrochemical method. Figure 4a shows the potentiodynamic polarization measurements data for copper (black curve) and graphene-coated copper (red curve). The data was recorded under high overpotential with electrochemical reaction governed by the Butler-Volmer equation [40]. Thus, a fit (dash line in Figure 4a) to the logarithmic relationship of the current density (I) vs. the electrode potential (V) can provide the redox reaction rate [40]. In the process of corrosion, the anodic dissolution rate of $\mathrm{Cu}$ at a specific potential is determined by the anodic current densities stemming from the rate of redox reaction [41]. 
(a)

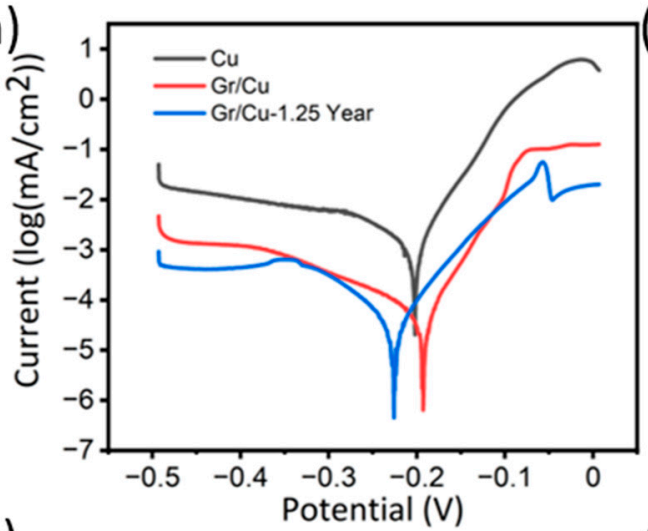

(c)

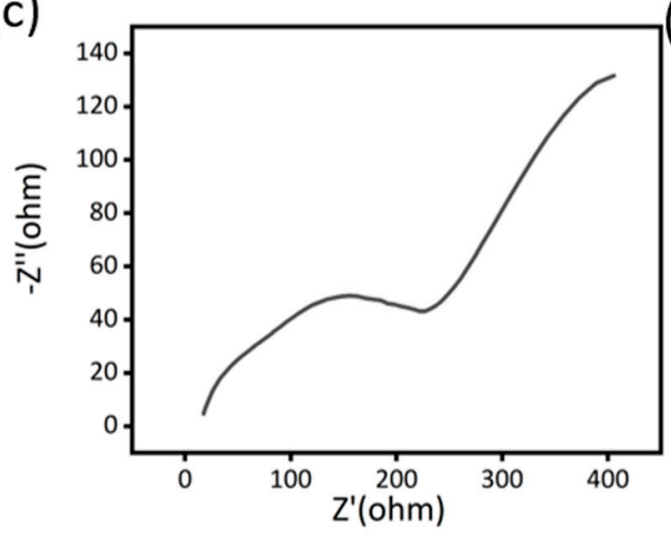

(b)

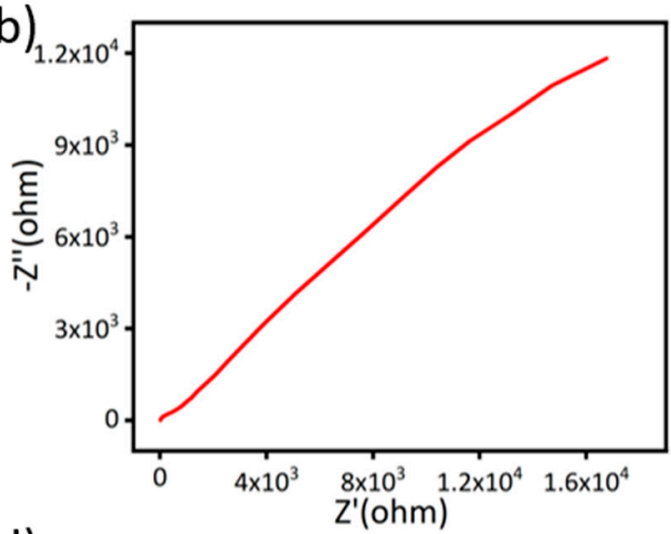

(d)

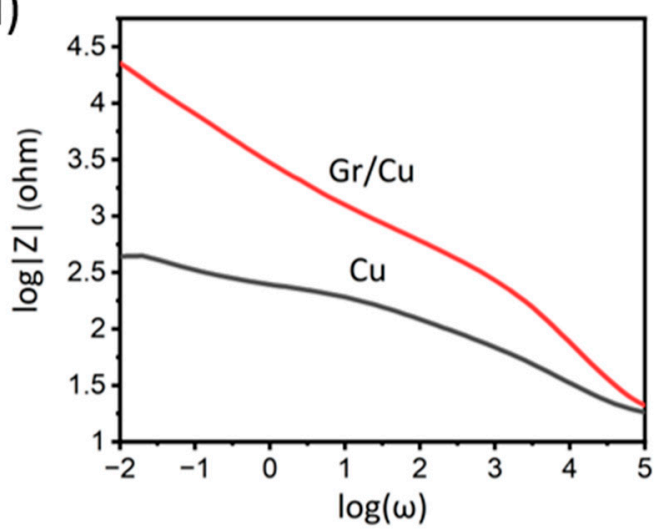

Figure 4. (a) Potentiodynamic polarization of the pure $\mathrm{Cu}$, graphene coated sample $(\mathrm{Gr} / \mathrm{Cu})$ and graphene-coated sample tested after 1.25 year $(\mathrm{Gr} / \mathrm{Cu}-1.25$ Year). (b) Nyquist plots of the $\mathrm{Gr} / \mathrm{Cu}$ and $\mathrm{Gr} / \mathrm{Cu}-1.25$ Year. (c) Nyquist plots of the $\mathrm{Cu}$. (d) Bode magnitude plots of $\mathrm{Gr} / \mathrm{Cu}-1.25$ Year, $\mathrm{Gr} / \mathrm{Cu}$ and Cu sample.

Consequently, potentiodynamic polarization was applied for the quantitative determination of corrosion rates. From Figure $4 \mathrm{a}$, we can see that the anodic current densities of the $\mathrm{Cu}$ samples were nearly one order of magnitude higher than the graphene-coated samples. For the determination of corrosion current, the calculation of Equivalent Weight $(E W)$ of copper is required, which can be calculated as below:

$$
E W=\frac{\text { Atomic Weight of } \mathrm{Cu}}{\text { Valency of } \mathrm{Cu}}
$$

The calculation for the corrosion rate $(C R)$ can be determined by this equation $[34,42]$ :

$$
C R=\frac{I_{\text {corr }} \times K \times E W}{\rho A}
$$

Here, the atomic weight of $\mathrm{Cu}$ is $64 \mathrm{~g} / \mathrm{mol}$ and the valency is +2 . The operative area of each sample is $3 \mathrm{~cm}^{2}$, and $\rho$ the density of copper substrate is $8.91 \mathrm{~g} / \mathrm{cm}^{3}$, and the corrosion rate constant $\mathrm{K}=3272 \mathrm{~mm} /(\mathrm{A} \mathrm{cm}$ year) [42,43]. From the potentiodynamic polarization curve, the average corrosion current $\left(I_{\text {corr }}\right)$ of bare substrates and graphene-coated samples is $1.58 \times 10^{-3} \mathrm{~mA}$ and $6.51 \times 10^{-5} \mathrm{~mA}$, respectively.

After the calculation, the average $C R$ of the bare copper substrate is $1.97 \times 10^{-13} \mathrm{~m} / \mathrm{s}$. The graphene covered sample mitigates the corrosion, with an average CR of $8.08 \times 10^{-14} \mathrm{~m} / \mathrm{s}$, which is 24 times lower than the copper corrosion rate. This anti-corrosion effect is higher than the values reported previously [26,34], and with more top surface coverage. This is relatively higher than some traditional coatings such as using benzotriazole which reduces corrosion rate by 10 times [44-47]. 
Another electrochemical experiment applied to test the anti-corrosion ability of coating is EIS Nyquist plots are shown in Figure $4 b, c$ to describe the linear relationship between the real impedance $\left(Z^{\prime}\right)$ and the imaginary impedance $\left(Z^{\prime \prime}\right)[40]$.

$$
Z^{2}=Z^{\prime 2}+Z^{\prime \prime 2}
$$

According to the above equation, when the $Z^{\prime \prime}$ tends to be zero, the absolute value of impedance $Z$ is equal to that of $Z^{\prime}$ which can be approximated to the resistance of sample surface. Consequently, the diameter of the semicircle in the Nyquist plot can represent the ability of electron transfer in the graphene coating or the surface of a bare copper substrate [26]. It is evident from Figure $4 b, c$ that the graphene coating can dramatically increase the impedance of the sample surface and suppress the electron transfer [26,34].

In addition, we analysed the data in the form of bode plots which provides the relationship between impedance $Z$ and frequency $\omega$. In the whole process of $\omega$ decreasing, the $Z$ of coated samples exceed that of bare substrates. When the $\omega$ is sufficiently small (the y-intercept) and $Z$ mainly results from $Z^{\prime}[26,40]$, the impedance of the graphene coating sample is much higher compared with the copper substrate. The EIS results are consistent with the polarization results.

Moreover, to study the stability of anticorrosive behaviour, we conducted the corrosion test experiments on samples after 15 months of the first test. The samples were stored in an ambient environment. The potentiodynamic polarization results are shown in Figure 4a. As we can see, there is no significant change in corrosion current on samples tested after 1.25 years, suggesting the highly inert behaviour of our double layer graphene coating as previously observed by Ying et al. [39].

\section{Conclusions}

In this work, graphene films were grown by evaporating ethanol in a CVD system, and we found that the films can serve as anti-corrosive layers. Graphene films grown at a temperature of $850{ }^{\circ} \mathrm{C}$ for 5-6 min show excellent anti-corrosion property over significant surface coverage. Our study shows that good quality graphene films can be prepared using readily available ethanol as a carbon source in a CVD process. The potentiodynamic polarization and EIS also separately confirmed that, compared with bare $\mathrm{Cu}$ substrates, lower corrosion rate and higher impedance can be achieved by graphene coating.

Author Contributions: Conceptualization, D.J. and X.W.; methodology, D.J. and Y.Y.; investigation, D.J. and X.W. writing-original draft preparation, D.J. and T.F.; writing—review and editing, T.F., Y.Y., F.W. and R.J.; supervision, R.J. All authors have read and agreed to the published version of the manuscript.

Funding: This research received no external funding.

Acknowledgments: The Authors acknowledge the facilities and support form staff of SMaRT Centre and Mark Wainwright Analytical Centre, UNSW.

Conflicts of Interest: The authors declare no conflict of interest.

\section{References}

1. Vukasovich, M.S. A Glossary of Corrosion-Related Terms Used in Science and Industry; Society of Automotive Engineers, Inc.: Warrendale, PA, USA, 1995.

2. Parthiban, G.T.; Malarkodi, D.; Palaniswamy, N.; Venkatachari, G. Corrosion protection by acrylamide treatment for magnesium alloy metal matrix composite (MMC) reinforced with titanium boride. Surf. Eng. 2010, 26, 378-384. [CrossRef]

3. Maege, I.; Jaehne, E.; Henke, A.; Adler, H.J.P.; Bram, C.; Jung, C.; Stratmann, M. Ultrathin organic layers for corrosion protection. Macromol. Symp. 1998, 126, 7-24. [CrossRef]

4. Mathiyarasu, J.; Pathak, S.S.; Yegnaraman, V. Review on corrosion prevention of copper using ultrathin organic monolayers. Corros. Rev. 2011, 24, 307-322. [CrossRef] 
5. Tallman, D.E.; Spinks, G.; Dominis, A.; Wallace, G.G. Electroactive conducting polymers for corrosion control: Part 1. General introduction and a review of non-ferrous metals. J. Solid State Electrochem. 2002, 6, 73-84. [CrossRef]

6. Zheludkevich, M.L.; Salvado, I.M.; Ferreira, M.G.S. Sol-gel coatings for corrosion protection of metals. J. Mater. Chem. 2005, 15, 5099-5111. [CrossRef]

7. Mittal, V.K.; Bera, S.; Saravanan, T.; Sumathi, S.; Krishnan, R.; Rangarajan, S.; Velmurugan, S.; Narasimhan, S.V. Formation and characterization of bi-layer oxide coating on carbon-steel for improving corrosion resistance. Thin Solid Film. 2009, 517, 1672-1676. [CrossRef]

8. Segarra, M.; Miralles, L.; Diaz, J.; Xuriguera, H.; Chimenos, J.M.; Espiell, F.; Piñol, S. Copper and CuNi alloys substrates for HTS coated conductor applications protected from oxidation. In Materials Science Forum; Trans Tech Publications Ltd.: Zurich, Switzerland, 2003; Volume 426-432, pp. 3511-3516.

9. Tseng, H.C.; Hung, C.; Huang, C.C. An analysis of the formability of aluminum/copper clad metals with different thicknesses by the finite element method and experiment. Int. J. Adv. Manuf. Technol. 2010, 49, 1029-1036. [CrossRef]

10. Chan, Y.C.; Chen, H.W.; Chao, P.S.; Duh, J.G.; Lee, J.W. Microstructure control in TiAlN/SiNx multilayers with appropriate thickness ratios for improvement of hardness and anti-corrosion characteristics. Vacuum 2013, 87, 195-199. [CrossRef]

11. Zhang, P.; Nie, X.; Northwood, D.O. Influence of coating thickness on the galvanic corrosion properties of Mg oxide in an engine coolant. Surf. Coat. Technol. 2009, 203, 3271-3277. [CrossRef]

12. Ismach, A.; Druzgalski, C.; Penwell, S.; Schwartzberg, A.; Zheng, M.; Javey, A.; Bokor, J.; Zhang, Y. Direct chemical vapor deposition of graphene on dielectric surfaces. Nano Lett. 2010, 10, 1542-1548. [CrossRef]

13. Miszczyk, A.; Darowicki, K. Accelerated ageing of organic coating systems by thermal treatment. Corros. Sci. 2001, 43, 1337-1343. [CrossRef]

14. Stolyarova, E.; Kwang, T.R.; Ryu, S.; Maultzsch, J.; Kim, P.; Brus, L.E.; Heinz, T.F.; Hybertsen, M.S.; Flynn, G.W. High-resolution scanning tunneling microscopy imaging of mesoscopic graphene sheets on an insulating surface. Proc. Natl. Acad. Sci. USA 2007, 104, 9209-9212. [CrossRef] [PubMed]

15. Lee, C.; Wei, X.; Kysar, J.W.; Hone, J. Measurement of the elastic properties and intrinsic strength of monolayer graphene. Science 2008, 321, 385-388. [CrossRef] [PubMed]

16. Wen, X.; Joshi, R. 2D Materials based Metal Matrix Composites. J. Phys. D Appl. Phys. 2020, 53, 423001. [CrossRef]

17. Cho, D.-H.; Jung, J.; Kim, C.; Lee, J.; Oh, S.-D.; Kim, K.-S.; Lee, C. Comparison of frictional properties of CVD-grown MoS2 and graphene films under dry sliding conditions. Nanomaterials 2019, 9, 293. [CrossRef]

18. Saeed, M.; Alshammari, Y.; Majeed, S.A.; Al-Nasrallah, E. Chemical Vapour Deposition of Graphene-Synthesis, Characterisation, and Applications: A Review. Molecules 2020, 25, 3856. [CrossRef]

19. Li, X.; Cai, W.; An, J.; Kim, S.; Nah, J.; Yang, D.; Piner, R.; Velamakanni, A.; Jung, I.; Tutuc, E.; et al. Large-area synthesis of high-quality and uniform graphene films on copper foils. Science 2009, 324, 1312-1314. [CrossRef]

20. Wu, M.; Hou, B.; Shu, S.; Li, A.; Geng, Q.; Li, H.; Shi, Y.; Yang, M.; Du, S.; Wang, J.-Q. High Oxidation Resistance of CVD Graphene-Reinforced Copper Matrix Composites. Nanomaterials 2019, 9, 498. [CrossRef]

21. Nan, H.Y.; Ni, Z.H.; Wang, J.; Zafar, Z.; Shi, Z.X.; Wang, Y.Y. The thermal stability of graphene in air investigated by Raman spectroscopy. J. Raman Spectrosc. 2013, 44, 1018-1021. [CrossRef]

22. Kim, K.; Regan, W.; Geng, B.; Alemán, B.; Kessler, B.M.; Wang, F.; Crommie, M.F.; Zettl, A. High-temperature stability of suspended single-layer graphene. Phys. Status Solidi Rapid Res. Lett. 2010, 4, 302-304. [CrossRef]

23. Bunch, J.S.; Verbridge, S.S.; Alden, J.S.; Van Der Zande, A.M.; Parpia, J.M.; Craighead, H.G.; McEuen, P.L. Impermeable atomic membranes from graphene sheets. Nano Lett. 2008, 8, 2458-2462. [CrossRef]

24. Chen, S.; Brown, L.; Levendorf, M.; Cai, W.; Ju, S.Y.; Edgeworth, J.; Li, X.; Magnuson, C.W.; Velamakanni, A.; Piner, R.D.; et al. Oxidation resistance of graphene-coated $\mathrm{Cu}$ and $\mathrm{Cu} / \mathrm{Ni}$ alloy. ACS Nano 2011, 5, 1321-1327. [CrossRef] [PubMed]

25. Kirkland, N.T.; Schiller, T.; Medhekar, N.; Birbilis, N. Exploring graphene as a corrosion protection barrier. Corros. Sci. 2012, 56, 1-4. [CrossRef]

26. Singh Raman, R.K.; Chakraborty Banerjee, P.; Lobo, D.E.; Gullapalli, H.; Sumandasa, M.; Kumar, A.; Choudhary, L.; Tkacz, R.; Ajayan, P.M.; Majumder, M. Protecting copper from electrochemical degradation by graphene coating. Carbon N. Y. 2012, 50, 4040-4045. [CrossRef] 
27. Schriver, M.; Regan, W.; Gannett, W.J.; Zaniewski, A.M.; Crommie, M.F.; Zettl, A. Graphene as a long-term metal oxidation barrier: Worse than nothing. ACS Nano 2013, 7, 5763-5768. [CrossRef]

28. Zhou, F.; Li, Z.; Shenoy, G.J.; Li, L.; Liu, H. Enhanced room-temperature corrosion of copper in the presence of graphene. ACS Nano 2013, 7, 6939-6947. [CrossRef]

29. Wu, Y.; Zhu, X.; Zhao, W.; Wang, Y.; Wang, C.; Xue, Q. Corrosion mechanism of graphene coating with different defect levels. J. Alloys Compd. 2019, 777, 135-144. [CrossRef]

30. Braeuninger-Weimer, P.; Burton, O.J.; Zeller, P.; Amati, M.; Gregoratti, L.; Weatherup, R.S.; Hofmann, S. Crystal Orientation Dependent Oxidation Modes at the Buried Graphene-Cu Interface. Chem. Mater. 2020, 32, 7766-7776. [CrossRef]

31. Xu, X.; Yi, D.; Wang, Z.; Yu, J.; Zhang, Z.; Qiao, R.; Sun, Z.; Hu, Z.; Gao, P.; Peng, H. Greatly enhanced anticorrosion of $\mathrm{Cu}$ by commensurate graphene coating. Adv. Mater. 2018, 30, 1702944. [CrossRef]

32. Mattevi, C.; Kim, H.; Chhowalla, M. A review of chemical vapour deposition of graphene on copper. J. Mater. Chem. 2011, 21, 3324-3334. [CrossRef]

33. Brownson, D.A.C.; Banks, C.E. The electrochemistry of CVD graphene: Progress and prospects. Phys. Chem. Chem. Phys. 2012, 14, 8264-8281. [CrossRef] [PubMed]

34. Prasai, D.; Tuberquia, J.C.; Harl, R.R.; Jennings, G.K.; Bolotin, K.I. Graphene: Corrosion-inhibiting coating. ACS Nano 2012, 6, 1102-1108. [CrossRef] [PubMed]

35. You, Y.; Yoshimura, M.; Cholake, S.; Lee, G.H.; Sahajwalla, V.; Joshi, R. A Controlled Carburization Process to Obtain Graphene-Fe3C-Fe Composites. Adv. Mater. Interfaces 2018, 5, 5. [CrossRef]

36. Guermoune, A.; Chari, T.; Popescu, F.; Sabri, S.S.; Guillemette, J.; Skulason, H.S.; Szkopek, T.; Siaj, M. Chemical vapor deposition synthesis of graphene on copper with methanol, ethanol, and propanol precursors. Carbon N. Y. 2011, 49, 4204-4210. [CrossRef]

37. Ferrari, A.C. Raman spectroscopy of graphene and graphite: Disorder, electron-phonon coupling, doping and nonadiabatic effects. Solid State Commun. 2007, 143, 47-57. [CrossRef]

38. Ferrari, A.C.; Basko, D.M. Raman spectroscopy as a versatile tool for studying the properties of graphene. Nat. Nanotechnol. 2013, 8, 235-246. [CrossRef]

39. Xu, Y.; Qu, J.; Shen, Y.; Feng, W. Different graphene layers to enhance or prevent corrosion of polycrystalline copper. RSC Adv. 2018, 8, 15181-15187. [CrossRef]

40. Bard, A.J.; Faulkner, L.R. Electrochemical Methods: Fundamentals and Applications; Wiley: New York, NY, USA, 1980; Volume 30, ISBN 3175723993.

41. McCafferty, E. Validation of corrosion rates measured by the Tafel extrapolation method. Corros. Sci. 2005, 47, 3202-3215. [CrossRef]

42. Yuan, S.; Pehkonen, S.O.; Liang, B.; Ting, Y.P.; Neoh, K.G.; Kang, E.T. Poly(1-vinylimidazole) formation on copper surfaces via surface-initiated graft polymerization for corrosion protection. Corros. Sci. 2010, 52, 1958-1968. [CrossRef]

43. Devgan, S.; Sidhu, S.S. Potential of electrical discharge treatment incorporating MWCNTs to enhance the corrosion performance of the $\beta$-titanium alloy. Appl. Phys. A Mater. Sci. Process. 2020, 126, 1-16. [CrossRef]

44. Zhang, D.; Lu, J.; Shi, C.; Zhang, K.; Li, J.; Gao, L. Anti-corrosion performance of covalent layer-by-layer assembled films via click chemistry reaction on the copper surface. Corros. Sci. 2021, 178, 109063. [CrossRef]

45. Peng, S.; Zhao, W.; Li, H.; Zeng, Z.; Xue, Q.; Wu, X. The enhancement of benzotriazole on epoxy functionalized silica sol-gel coating for copper protection. Appl. Surf. Sci. 2013, 276, 284-290. [CrossRef]

46. Finšgar, M.; Milošev, I. Inhibition of copper corrosion by 1,2,3-benzotriazole: A review. Corros. Sci. 2010, 52, 2737-2749. [CrossRef]

47. Gelman, D.; Starosvetsky, D.; Ein-Eli, Y. Copper corrosion mitigation by binary inhibitor compositions of potassium sorbate and benzotriazole. Corros. Sci. 2014, 82, 271-279. [CrossRef]

Publisher's Note: MDPI stays neutral with regard to jurisdictional claims in published maps and institutional affiliations. 